\title{
Improvement of flock productivity through supply of vitamins for higher laying performance and better egg quality
}

\author{
G.M. WEBER \\ CH-4002 Basel, Switzerland \\ Corresponding author: gilbert.weber@dsm.com
}

DSM Nutritional Products Ltd, R\&D Animal Nutrition and Health, PO Box 2676,

An adequate supply of all nutrients, including proteins, fats, carbohydrates, vitamins, minerals and water, has to be provided to support maximum productivity of laying hens. Among these nutrients, vitamins are particularly important, since they are essential for optimum health as well as normal physiological functions of the hens. As most vitamins cannot be synthesized by poultry in sufficient amounts to meet physiological demand, they must be obtained from the diet. The absence from feed or impaired absorption or utilization of vitamins can lead to specific deficiency disorders. This review reports on the occurrence and the physiological functions of all vitamins and summarizes research related to the requirements for and the beneficial effects of supplemental vitamins for laying hens. The recommendations for dietary supplementation of vitamins from various organizations are compared and put into perspective of modern poultry genotypes and current husbandry conditions. As there is good evidence that the minimum dietary vitamin levels, required to prevent clinical deficiencies may not support optimum health, performance and welfare of poultry under today's conditions it is recommended to include a safety margin to the vitamin requirements of laying hens.

Keywords: layers; egg quality; vitamins; productivity

\section{Introduction}

The overall goal of the layer industry is to achieve the best performance, feed utilization and health of birds. All nutrients including proteins, fats, carbohydrates, vitamins, minerals and water are essential for these vital functions, but vitamins have an additional dimension. They are required in adequate levels to enable the animal to efficiently utilize all other nutrients in the feed. Therefore, optimum nutrition occurs only when the bird is offered the correct mix of macro- and micro-nutrients in the feed 
and is able to efficiently utilize those nutrients for its growth, health, reproduction and survival.

Vitamins are active substances, essential for life of man and animals. They belong to the micronutrients group and are required for normal metabolism in animals. Vitamins are essential for optimum health as well as normal physiological functions such as growth, development, maintenance and reproduction. As most vitamins cannot be synthesized by poultry in sufficient amounts to meet physiological demands, they must be obtained from the diet. Vitamins are present in many feedstuffs in minute amounts and can be absorbed from the diet during the digestive process. If vitamins are absent from the diet or improperly absorbed or utilized, specific diseases or deficiency syndromes occur.

Classically, vitamins have been divided into two groups based on their solubility in lipids or in water. The fat-soluble group includes the vitamins $\mathrm{A}, \mathrm{D}, \mathrm{E}$ and $\mathrm{K}$, while vitamins of the $\mathrm{B}$ complex $\left(\mathrm{B}_{1}, \mathrm{~B}_{2}, \mathrm{~B}_{6}, \mathrm{~B}_{12}\right.$, niacin, pantothenic acid, folic acid and biotin) as well as vitamin $\mathrm{C}$ are classified as water-soluble. Fat-soluble vitamins are found in feedstuffs in association with lipids. The fat-soluble vitamins are absorbed along with dietary fats, apparently by mechanisms similar to those involved in fat absorption. Uptake of water-soluble vitamins occurs usually via simple diffusion. Fat-soluble vitamins may be stored in the animal body. In contrast to that, water-soluble vitamins are not stored and excesses are rapidly excreted.

In the following sections, the physiological functions and their effects in laying hens are described. An overview on the dietary levels, recommended by the National Research Council (NRC, 1994), a German Trade Association (AWT, 2002) and a vitamin manufacturer (DSM, 2006) are given in Table 1, and put into perspective of research on vitamin requirements over the last decades.

Table 1 Recommended levels of all vitamins by NRC (1994), AWT (2002) and DSM (2006).

\begin{tabular}{llll}
\hline Vitamin & NRC $\mathbf{1}, \mathbf{1 9 9 4}$ & AWT $^{\mathbf{2}, \mathbf{2 0 0 2}}$ & DSM $^{\mathbf{2}, \mathbf{2 0 0 6}}$ \\
\hline Vitamin A (IU/kg) & $2,500-3,750$ & $8,000-12,000$ & $8,000-12,000$ \\
Vitamin $\mathrm{D}_{3}(\mathrm{IU} / \mathrm{kg})$ & $250-375$ & $2,000-3,000$ & $2,500-3,500$ \\
Vitamin E (mg/kg) & $4-6$ & $20-30$ & $15-30$ \\
Vitamin $\mathrm{K}_{3}(\mathrm{mg} / \mathrm{kg})$ & $0.4-0.6$ & $2.0-3.0$ & $2.0-3.0$ \\
Vitamin B $(\mathrm{mg} / \mathrm{kg})$ & $0.6-0.9$ & $2.0-3.0$ & $1.5-3.0$ \\
Vitamin $\mathrm{B}_{2}(\mathrm{mg} / \mathrm{kg})$ & $2.1-3.1$ & $5.0-8.0$ & $4.0-7.0$ \\
Vitamin B $(\mathrm{mg} / \mathrm{kg})$ & $2.1-3.1$ & $3.0-5.0$ & $3.0-5.0$ \\
Vitamin $\mathrm{B}_{12}(\mathrm{mg} / \mathrm{kg})$ & 0.004 & $0.015-0.025$ & $0.015-0.025$ \\
Niacin $(\mathrm{mg} / \mathrm{kg})$ & $8.3-12.5$ & $25-40$ & $20-50$ \\
Pantothenic Acid $(\mathrm{mg} / \mathrm{kg})$ & $1.7-2.5$ & $8-10$ & $8-10$ \\
Folic Acid $(\mathrm{mg} / \mathrm{kg})$ & $0.2-0.3$ & 1.0 & $0.5-1.0$ \\
Biotin $(\mathrm{mg} / \mathrm{kg})$ & $0.08-0.13$ & $0.05-0.08$ & $0.10-0.15$ \\
Vitamin C (mg/kg) & 0 & $100-150$ & $100-200$ \\
\hline
\end{tabular}

\footnotetext{
1 NRC values are estimates of the minimum vitamin requirement in terms of total dietary (available) concentration, based on a daily feed intake in the range of 80 to $120 \mathrm{~g}$ per day.

${ }^{2}$ Commercial values are supplemental amounts to be added above the natural vitamin content of the diet, based on a daily feed intake in the range of 80 to $120 \mathrm{~g}$ per day.
}

\section{Vitamin A (Retinol)}

Retinol can only be found in animal tissues, while the provitamin A, beta-carotene, occurs predominantly in the vegetable kingdom. Dietary retinyl-esters are hydrolyzed 
in the intestinal lumen and the alcoholic form of vitamin $\mathrm{A}$ is actively absorbed in association with low density lipoproteins. In the intestinal wall, retinol is re-esterified and transported via the blood stream to the liver and the kidneys were it is stored in the form of vitamin A esters. From there it is mobilized through hydrolysis, distributed to the cells as retinol via the blood stream (bound to retinol binding protein) and transformed into the active compound, retinoic acid. Vitamin A is essential for normal vision; it supports the development and maintains the integrity of epithelia as well as of the skeleton. In farm animals, vitamin A is important for normal feed intake, growth and performance. Furthermore, it supports an optimum immune response and thereby reduces the susceptibility to infection.

Vitamin A deficiency induces loss of appetite, growth retardation or inhibition and can result in death. Affected birds develop a dry and scaly skin, rough plumage and metaplasia of respiratory epithelia, which increases the risk of infections. Keratinisation of epithelia in the digestive tract depresses gland activities and results in poor absorption of nutrients. In laying hens a severe degeneration of the ovary can occur, inducing a marked decline in egg production.

In a series of experiments, Richter et al. (1990) established that a minimum of 5,000 IU vitamin A per kg are necessary to allow adequate feed intake and laying performance during lay. However, no benefits could be demonstrated if higher than this dietary vitamin A level was fed, probably due to the limited genetic potential of those hens at the time. The performance of laying hens fed on vitamin A deficient diets was shown to decline significantly, but egg weight and shell thickness were not consistently changed. Vitamin A levels of egg yolk were found not to be related to dietary level, and therefore are not useful to predict future vitamin A deficiency in laying hens (Squires and Naber, 1993a). In heat-stressed commercial layers it was demonstrated that a high level of dietary vitamin A $(12,000 \mathrm{IU} / \mathrm{kg})$ improved the laying performance and immune function of hens (Lin et al., 2002). Feed intake and laying rate was beneficially influenced and the egg weight of heat-stressed hens increased. A good vitamin A supply is essential when rearing replacements for future laying flocks. When pullets from marginally vitamin A deficient hens were fed with low levels of vitamin A, plasma concentrations of retinol dropped considerably, body weights were lower than that of the respective controls and more of the vitamin A-deficient birds died (Beynen et al., 1989).

Since poultry under commercial husbandry conditions are always more vulnerable to infectious diseases, the effect of vitamin A on the immune response was further investigated. Coşkun et al. (1998) investigated dietary levels of up to 24,000 IU vitamin A per $\mathrm{kg}$ feed in laying hens over one year, but could not find any beneficial effects on various parameters of immune responses. In contrast to that finding, a high level of dietary vitamin A $(12,000 \mathrm{IU} / \mathrm{kg})$ increased the antibody titre against Newcastle disease virus (NDV) of heat-stressed hens (Lin et al., 2002).

\section{Vitamin $D_{3}$ (cholecalciferol)}

The active form of vitamin D is not widely distributed in nature; but vitamin D precursors are present in many vegetables. Poultry can only utilize vitamin $\mathrm{D}_{3}$, i.e. vitamin $\mathrm{D}_{2}$ has no physiological value in this species. Rich sources of vitamin $\mathrm{D}_{3}$ include liver and viscera of fish. Cholecalciferol is absorbed from the intestinal tract in conjunction with fats, and so the presence of bile salts is needed for absorption. Vitamin $\mathrm{D}_{3}$ is first taken up by the liver and finally deposited in adipose tissue. In the liver, cholecalciferol is converted to 25 -hydroxy-cholecalciferol $\left(25(\mathrm{OH}) \mathrm{D}_{3}\right)$ and then further hydroxylated in the 
kidney to 1,25 -dihydroxy-cholecalciferol $\left(1,25(\mathrm{OH})_{2} \mathrm{D}_{3}\right)$. The last transformation step to the active hormonal form of vitamin $\mathrm{D}_{3}$ is under the control of the parathyroid hormone. Vitamin $\mathrm{D}$ regulates the homeostasis of calcium $(\mathrm{Ca})$ and phosphorous $(\mathrm{P})$, i.e. it increases the absorption of calcium and phosphorous from the small intestine as well as the re-absorption of these minerals in the renal tubules and influences the calcification process by increasing the uptake of minerals by the bones.

Clinical deficiency signs include inhibition of growth, loss of weight, reduced or lost appetite and high mortality. The epiphyses are enlarged, with the bones of the extremities, vertebral column and cranium becoming deformed and brittle. The beak of rachitic chicks is typically soft and pliant. Animals move stiffly and hesitantly due to the high incidence of lameness and muscular weakness. In layers, egg production decreases and eggs with thin shells are laid.

The fundamental effects of vitamin $\mathrm{D}_{3}$ in laying and breeding poultry have mainly been elucidated by study of the adverse effects of deficiency. In adult laying hens, vitamin $\mathrm{D}_{3}$ deficiency produces osteomalacia. This is characterized by a decreased concentration of $\mathrm{Ca}$ and $\mathrm{P}$ in the bone matrix. Furthermore vitamin $\mathrm{D}_{3}$ deficiency reduces egg production and egg weight and increases the occurrence of thin shells, cracks and deformities. When laying Japanese quails were fed a vitamin D-deficient diet, their eggshell weights and egg production rate were reduced. The calcium content of the medullary bone of the femur decreased markedly with the progress of vitamin D deficiency, whereas that of the cortical bone remained unchanged. Administration of vitamin $\mathrm{D}_{3}$ to deficient quail has been shown to increase the mineralization of medullary bone (Takahashi et al., 1983).

Egg shell pimpling, which is one of the various types of egg shell problems in the industry today, is directly and inversely related to the level of cholecalciferol in the diet (Goodson-Williams et al., 1986). When supplemental vitamin $\mathrm{D}_{3}$ was removed from the feed of White Leghorn hens, egg weight, egg specific gravity, shell weight, percent shell, shell thickness, and plasma calcium were reduced (Grunder and Tsang, 1984). Only 4 weeks is required on a vitamin $\mathrm{D}_{3}$-deficient diet to reduce the thickness of the shell and induce the production of numerous thin-shelled and soft-shelled eggs. The outer layers of the shell may be reduced or absent, but the inner mammillary layer is always present, suggesting that the hens stop laying before $\mathrm{Ca}$ concentrations in blood become too low for the formation of the mammillary knobs. Uncalcified portions of the shell organic matrix are not found, suggesting that $\mathrm{Ca}$ deposition and matrix formation are inhibited simultaneously (Narbaitz et al., 1987). Withdrawal of cholecalciferol from a layer diet drastically reduced blood $25(\mathrm{OH}) \mathrm{D}_{3}, 1,25(\mathrm{OH})_{2} \mathrm{D}_{3}$ and egg specific gravity within two weeks, which was followed by a decrease in blood total Ca. Doubling the vitamin $\mathrm{D}_{3}$ supplement in the control diet to $1,100 \mathrm{IU} / \mathrm{kg}$ almost linearly increased the circulating concentration of $25(\mathrm{OH}) \mathrm{D}_{3}$ without raising the concentration of $1,25(\mathrm{OH})_{2} \mathrm{D}_{3}$ or of $\mathrm{Ca}$ (Tsang and Grunder, 1993).

\section{VITAMIN $D_{3}$ METABOLITES}

In laying hens kept under commercial conditions, clinical signs of vitamin $\mathrm{D}_{3}$ deficiency, such as cage-layer-fatigue or thin-shelled eggs, are frequently observed, indicating insufficient utilization of the dietary vitamin $\mathrm{D}_{3}$. Supplementing an already activated form of vitamin $\mathrm{D}_{3}$, such as one of the $\mathrm{D}_{3}$-metabolites, has been proposed to counteract such problems. Recently, $25(\mathrm{OH}) \mathrm{D}_{3}$, representing the first metabolite in the cascade of vitamin D mobilization, has become commercially available to the poultry industry under the tradename $\mathrm{Hy} \cdot \mathrm{D}^{\circledR}$. This $25(\mathrm{OH}) \mathrm{D}_{3}$ form has been demonstrated to support the homeostatic function of vitamin $\mathrm{D}_{3}$ for the absorption of $\mathrm{Ca}$ and $\mathrm{P}$ in order to 
provide sufficient minerals for the development of the bone and the eggshell (Soares et al., 1995).

Practical studies have shown that replacing vitamin $\mathrm{D}_{3}$ partly by $25(\mathrm{OH}) \mathrm{D}_{3}$ improved laying performance, decreased the number of broken eggs and increased egg weight, egg mass as well as the number of extra-large eggs (Soto-Solanova and Hernandez, 2004). In addition egg yolk susceptibility to oxidation was decreased and the loss of egg mass during storage was numerically reduced. Likewise, under commercial conditions a numerical improvement of laying performance with $25(\mathrm{OH}) \mathrm{D}_{3}$ supplementation was observed (Soto-Solanova and Schliffka, 2007).

\section{Vitamin E}

Among the richest sources of vitamin E are cereal germs and certain oilseeds. Within the group of tocopherols, alpha-tocopherol is the most effective vitamin E compound for poultry. Uptake is linked to fat absorption, again facilitated by the presence of bile salts. There is a negative interaction with the absorption of vitamin A (high A levels depress $\mathrm{E}$ absorption). Transport from the intestine to the systemic circulation runs via chylomicrons of the lymph. In plasma, vitamin E is bound to lipoproteins; storage of vitamin $\mathrm{E}$ occurs in the liver.

Vitamin E (alpha-tocopherol) is nature's most powerful fat-soluble antioxidant and as such is important to protect the phospholipids of cellular and sub-cellular membranes from destruction by lipid oxidation and accordingly to maintain the morphological integrity and functionality of cells and tissues of the organism. Furthermore, as an essential micronutrient, vitamin $\mathrm{E}$ optimises performance and reproduction of farm animals. In poultry, vitamin $\mathrm{E}$ protects the ovarian follicles from oxidative damage and there is evidence that it also facilitates the release of vitellogenin as a precursor of the yolk from the liver and thus has an important function in egg production. Due to its modulatory effect on the immune system (e.g. the activation of macrophages and production of antibodies) alpha-tocopherol has proven effective for the prevention and resistance against various diseases. Signs of clinical vitamin E deficiency include muscular myopathy, exudative diathesis (abnormal permeability of the capillary walls) and disturbance of the nervous system (encephalomalacia in chicks). More often subclinical vitamin E deficiency occurs, which is manifested as slow growth, reduced productivity, frequent health problems and diminished fertility. In animal nutrition, vitamin $\mathrm{E}$ is usually supplied in its stable ester form as alpha-tocopheryl acetate.

Several attempts have been made to determine the vitamin E requirement of laying hens. More than 20 years ago, Richter et al. (1986) performed a series of experiments with laying hens supplemented with vitamin $\mathrm{E}$ at $20 \mathrm{mg} / \mathrm{kg}$ against an unsupplemented control diet. Due to absence of any measurable effects of vitamin $E$ on laying performance, feed efficiency or mortality, the authors concluded that the natural content $(>1 \mathrm{mg}$ alpha-tocopherol $/ \mathrm{kg}$ ) of the diet was sufficient for an adequate performance of laying hens. Later, Scheideler and Froning (1996) demonstrated that a dietary supplementation of hens with $50 \mathrm{mg} / \mathrm{kg}$ instead of $27 \mathrm{mg} / \mathrm{kg}$ improved egg production, which proved the essential function of vitamin $\mathrm{E}$ for optimizing performance of laying hens. In a study investigating immune response, the combination of $65 \mathrm{ppm}$ vitamin $\mathrm{E}$ and $1,000 \mathrm{ppm}$ vitamin $\mathrm{C}$ during heat stress showed the highest lymphocyte proliferative responses to concanavalin $\mathrm{A}$ and Salmonella typhimurium lipopolysaccharide in comparison to treatments with lower E supplementation (Puthpongsiriporn et al., 2001). This result indicates an important function of vitamin $\mathrm{E}$ for maintenance of health of laying hens. 
In layers subjected to high ambient temperatures, basic vitamin E requirements were found to be higher. Under conditions of chronic heat stress, vitamin E supplementation of $500 \mathrm{mg} / \mathrm{kg}$ was necessary to alleviate the adverse effects on egg production and egg weight (Bollengier-Lee et al., 1998). If the supplemented diet was provided before, during and after heat stress, a reduced dietary dose of $250 \mathrm{mg}$ vitamin E per $\mathrm{kg}$ was found to be optimum for alleviating the adverse effects of chronic heat stress in laying hens (Bollengier-Lee et al., 1999).

Vitamin E is a particularly safe micronutrient, as supplementation up to $20,000 \mathrm{mg} / \mathrm{kg}$ did not impact on performance of hens. As expected, a dose-dependent increase in alphatocopherol concentration in plasma, liver, muscle and egg yolk was found (Sünder and Flachowsky, 2001). Higher dietary supplementation levels of vitamin E have been used to improve the oxidative stability of the egg yolk, particularly when polyunsaturated fatty acids (PUFAs) were used. Grune et al. (2001) added fish oil to the diet of laying hens, which were supplemented from 0 up to $160 \mathrm{mg}$ vitamin $\mathrm{E}$ per $\mathrm{kg}$ diet. Egg yolks contained more n-3 PUFAs, mainly due to accumulation of docosahexaenoic acid. To prevent the increase of lipid peroxidation during production and storage of n-3 PUFAenriched eggs, a high vitamin E supplementation with at least $80 \mathrm{mg} / \mathrm{kg}$ was needed. Further processing of eggs increases the requirement for stabilization of lipids. When eggs enriched with PUFAs were submitted to an atomization process followed by spraydrying, the oxidation values increased 10 to 12 -fold over the values of fresh eggs. Only supplementation of hens with $200 \mathrm{ppm}$ vitamin E significantly reduced lipid oxidation in comparison to the standard level of $50 \mathrm{ppm}$ (Galobart et al., 2001). Accordingly, vitamin E contributes substantially to the quality of eggs during processing.

\section{EGG ENRICHMENT}

When alpha-tocopherol and beta-carotene, two antioxidants which are associated with health benefits for humans and animals, were supplemented in laying hen diets at levels of up to $400 \mathrm{mg} / \mathrm{kg}$ each, their concentration in chicken egg yolks could be significantly improved. Alpha-tocopherol increased from the control level of $144 \mathrm{ug} / \mathrm{g}$ of yolk to 477 $\mathrm{ug} / \mathrm{g}$ of yolk (at $400 \mathrm{ppm}$ vitamin E), and yolk retinol levels increased from $11.6 \mathrm{ug} / \mathrm{g}$ in controls to $13.9 \mathrm{ug} / \mathrm{g}$ at $200 \mathrm{ppm}$ beta-carotene. Beta-carotene content in the yolk also increased from $0.14 \mathrm{ug} / \mathrm{g}$ of yolk in controls to $5.19 \mathrm{ug} / \mathrm{g}$ of yolk, when supplied at levels of $200 \mathrm{mg} / \mathrm{kg}$ diet. Supplemental beta-carotene markedly decreased the yolk deposition of alpha-tocopherol when the two compounds were fed together (Jiang et al., 1994). When feeding very high doses of vitamin E $(100,1000,10,000$ and $20,000 \mathrm{mg} / \mathrm{kg})$ over a period of 20 weeks, no significant influence on health or performance of hens was observed. Vitamin E content of eggs increased from 1 to 4, 21, 46 and $51 \mathrm{mg}$ per egg with vitamin E supplementation, which represents a considerable enrichment of eggs with vitamin E (Sünder et al., 1999).

In order to overcome dietary deficits, multiple-enriched eggs have been obtained by feeding laying hens with linseed, minerals, vitamins and lutein. These eggs have greater nutritional value than standard eggs, containing six times more omega-3 fatty acid (ALA), three times more DHA, three times more vitamin D, four times more folic acid, six times more vitamin E, six times more lutein and zeaxanthine, two and a half times more iodine and four times more selenium. Furthermore these eggs are rich in vitamin $\mathrm{B}_{12}$ and vitamin $\mathrm{A}$, plus vitamin $\mathrm{B}_{2}$, vitamin $\mathrm{B}_{5}$ (pantothenic acid) and phosphorus (Bourre and Galea, 2006). 


\section{Vitamin K}

The absorption of vitamin $\mathrm{K}$ happens in association with dietary fats, facilitated by the presence of bile salts. Vitamin $\mathrm{K}_{3}$ (menadione) is the main source in animal nutrition. Following absorption, vitamin $\mathrm{K}$ is metabolized in the liver. Very little is stored; which results in rapid depletion, probably within one week, if dietary supply is low.

Vitamin K regulates the production of certain coagulation factors in the blood plasma $e$. $g$. prothrombin and clotting factors VII, IX and X, preventing uncontrolled bleeding from wounds. These factors are proteins, produced in the liver, and their synthesis depends on the presence of minute quantities of vitamin K. Deficiency of this vitamin increases blood-clotting time, resulting in hemorrhagic diseases in most tissues and organs. In young poultry general weakness, rough plumage and paleness as well as icteric coloration of the comb, the wattles and eye-lids as a result of anaemia have been described. Subcutaneous and intramuscular haemorrhages and bloody faeces due to bleeding in the crop and in the caeca can occur. The specific activity of vitamin $\mathrm{K}$ could also be of importance in laying hens, which are injured by management practice (beak trimming) or nervous behaviour (cannibalism). Having an optimum blood clotting, hens might avoid more severe problems due to blood loss and enable a faster healing as a consequence of such events.

Vitamin $\mathrm{K}$ is also important in relation to bone formation and bone re-modelling. Osteocalcin, one of the main bone proteins, is dependent on vitamin K. Osteocalcin is found in bone, the uterus and eggshell. Low levels of osteocalcin can interfere with bone mineralization during skeletal development and eggshell formation. Furthermore, a link between sub-optimal vitamin $\mathrm{K}$ supply and osteoporosis in laying hens has been proposed by Fleming (2008). Therefore the supplementation of laying feeds with 2 to $3 \mathrm{mg}$ menadione per $\mathrm{kg}$ diet is recommended. In order to determine the effect of vitamin $\mathrm{K}$ deficiency on indices of skeletal metabolism in laying hens, the birds were fed a vitamin K-deficient diet for 28 weeks, which resulted in impaired blood clotting and reduced bone gamma-carboxyglutamic acid concentration compared with vitamin $\mathrm{K}$ sufficient hens. However, this treatment did not influence egg production, eggshell deposition or other reproductive performance criteria (Lavelle et al., 1994). In conflict with these findings, Fleming et al. (2003) found that additional vitamin $\mathrm{K}_{3}(10 \mathrm{mg} / \mathrm{kg})$ resulted in higher proximal tarsometatarsus cancellous bone volumes at 15 weeks and throughout the laying period compared with controls. Vitamin $\mathrm{K}$ also prolonged the modelling period of bone formation or the inhibition of medullary bone loss during the first phases of lay. Plasma osteocalcin concentrations, however, were unaffected by vitamin $\mathrm{K}_{3}$ supplementation during growth.

\section{B-Vitamins}

The B vitamins have very important functions in avian metabolism, as most of them represent coenzymes, which fuse with larger enzyme molecules in order to accelerate various metabolic processes. Vitamins $\mathrm{B}_{1}, \mathrm{~B}_{2}, \mathrm{~B}_{6}$, niacin, pantothenic acid and biotin are all involved in the energy metabolism, while vitamin $\mathrm{B}_{12}$ and folic acid exert their activity on growth and cell maintenance. It is important to consider that B-vitamins that are involved in particular metabolic effects interact with each other, which makes it difficult to determine individual requirements for each vitamin within the B-group.

VITAMIN B B $_{1}$ (THIAMIN)

All vertebrates are almost completely dependent on dietary vitamin $B_{1}$ intake. 
Although bacteria are able to synthesize some thiamin in the intestinal tract (mainly in the caeca), this material is only accessible via coprophagy and accordingly caged laying hens cannot benefit from that. Thiamin is present in considerable concentrations in yeast, in cereals in soya and in oil seeds, but is not always entirely available to poultry. Thiamin is rapidly and actively absorbed from the small intestine and then transformed by phosphorylation into the active co-enzyme thiamin pyrophosphate. The body is incapable of storing free thiamin, but small amounts of the phosphorylated form is found in all animal cells. Dephosphorylation can occur in the kidney and excess quantities of the free vitamin are excreted in the urine or as uric acid in the case of birds.

The active co-enzyme of vitamin $\mathrm{B}_{1}$ is thiamin pyrophosphate (TPP). As a co-enzyme TPP is involved in oxidative decarboxylation of pyruvic acid and ketoglutaric acid. These reactions yield acetyl-coenzyme A (CoA) and succinyl-CoA and have a central function in the citric acid cycle, leading to complete degradation of carbohydrates. Accordingly, vitamin $B_{1}$ is important for the metabolism of carbohydrates, proteins and fats. Deficiency symptoms in poultry include loss of appetite, weight loss, general weakness and death. More particularly, fatty degeneration and necrosis of heart fibres, bradycardia, heart failure (sudden death syndrome) have been described, and fatty degeneration and haemorrhages of the liver can occur. Mucosal inflammation, ulcers and haemorrhages of the intestinal tract as well as skin oedema and cyanosis have been observed, and progressive paralysis may ultimately leads to death of the birds. In laying hens atrophied ovaries were observed, resulting in reduced egg production.

The main investigations into the vitamin $\mathrm{B}_{1}$ requirements of poultry are quite old and, based on this information, the current recommendations (NRC, 1994) are very low $(0.7$ $\mathrm{mg} / \mathrm{kg}$ ). The most recent requirement study for broiler chicks (Olkowski and Classen, 1996) showed that a vitamin $B_{1}$ supplementation level above $2 \mathrm{mg} / \mathrm{kg}$ did not result in better performance of chicks, but that a minimum of $8 \mathrm{mg} / \mathrm{kg}$ was necessary to avoid a decline in blood thiamin concentrations. This finding could be taken as an indication that modern birds, selected for high performance, have a superior requirement for vitamin $B_{1}$.

\section{VITAMIN B $\mathrm{B}_{2}$ (RIBOFLAVIN)}

Vitamin $B_{2}$ is widely distributed in all leafy vegetables, in the flesh of warm blooded animals and in fish. Riboflavin is stored in small quantities in liver, spleen, kidney and cardiac muscle; these depots are maintained and, even in severe deficiency states, remain at a steady level. Riboflavin is eliminated in the urine and the daily losses can amount up to $30 \%$ of intake.

Riboflavin is phosphorylated in the intestinal mucosa to flavin mononucleotide (FMN) during absorption, and then converted to flavin-adenin dinucleotide (FAD) in the liver. Riboflavin is an essential factor of flavin enzymes (flavoproteins). These enzymes are involved in the transport and transfer of hydrogen within the respiration chain, and thus contribute to energy production. Furthermore, they are important for both synthesis and degradation of fatty acids, which explains why vitamin $B_{2}$ requirement is increased on a high-fat diet. $\mathrm{B}_{2}$-containing amino acid oxidases also catalyze the oxidative catabolism of amino acids. Obvious deficiency signs in poultry include slow growth and reduced appetite. The mouth, nasal mucous membranes and skin of the extremities tend to get inflamed and muscular debility, trembling, spasms and paralysis, due to myelin degeneration of peripheral nerves (curled toe paralysis) can occur. Vomiting, resorption disorders and diarrhoea, due to inflammation of the mucous membranes of the digestive tract, have been described and in hens, egg laying is disturbed.

Squires and Naber (1993b) investigated the relationship between dietary riboflavin supplementation of laying hens $(1.55-8.8 \mathrm{mg} / \mathrm{kg})$ and egg production as well as riboflavin content in eggs. Egg production, egg weight, hatchability and hen weight 
were all significantly depressed by the two lower riboflavin levels, when compared with the higher levels. Results indicated that egg riboflavin concentrations were related to important production parameters that could be used to predict future dietary riboflavin inadequacies. A study with breeding hens, supplemented with 2.5 to $12.5 \mathrm{mg}$ riboflavin per $\mathrm{kg}$ and kept under conditions of a humid tropical environment, confirmed this finding. Out of the various productive parameters analysed, the only one which responded was egg production, increasing significantly, when the dietary riboflavin level was $8.5 \mathrm{mg} / \mathrm{kg}$ (Arijeniwa et al., 1996).

\section{VITAMIN B 6 (PYRIDOXINE)}

Vitamin $\mathrm{B}_{6}$, in its main forms pyridoxal and pyridoxamine, is widely distributed in low concentrations in all animal and plant tissues. In a glycosylated form, however, it is not entirely bioavailable. Absorption of pyridoxine occurs in the proximal jejunum, after which it is phosphorylated in the liver by pyridoxal kinase and released into the blood. Both pyridoxal phosphate and pyridoxamine phosphate are bound to albumen and distributed throughout animal tissues in form of co-enzymes. A large portion of absorbed vitamin $\mathrm{B}_{6}$ can be excreted in urine as the inactive metabolite, 4-pyridoxic acid. Pyridoxal phosphate and pyridoxamine phosphate are co-factors of various enzymes (e.g. transaminases, deaminases, desulphydrases and amino acid decarboxylases) and thus are essential for the metabolism of amino acids, which explains an increased requirement of vitamin $\mathrm{B}_{6}$ on a high-protein diet. Furthermore vitamin $\mathrm{B}_{6}$ is involved in both synthesis and transformation of glycogen and markedly influences the fatty acid metabolism via conversion of linoleic to arachidonic acid. Thus, pyridoxine is an essential element for energy production, fat metabolism, central nervous system activity and haemoglobin production. In case of pyridoxine deficiency a loss of appetite, slow growth and poor feed utilization in poultry has been observed. Dermatitis, rough and deficient plumage, inflamed oedema of eyelids, anaemia and ascites can also occur. Through demyelinisation of peripheral nerves, movements can appear un-coordinated, resulting ultimately in muscular convulsions, followed by paralysis. In laying hens, impaired egg laying performance, fertility and hatchability are induced by deficiency.

In a classical experiment with breeding hens, the vitamin $\mathrm{B}_{6}$ requirement was estimated at 1.5 to $2 \mathrm{mg}$ per $\mathrm{kg}$ of feed, based on the reproduction characteristics of the hens, which included laying performance (Abend et al., 1977). A certain benefit of higher pyridoxine supplementation levels of the hens was observed, when taking performance characteristics into account. It has to be mentioned that such requirement studies are usually carried out under optimum husbandry conditions. Stress and disease challenge may substantially increase the vitamin needs of farm animals. Accordingly, the practical recommendations are usually higher than the minimum requirements.

\section{VITAMIN B 12 (CYANOCOBALAMINE)}

Vitamin $B_{12}$ usually does not get a lot of attention in nutrition, since it is required at very low concentrations in feed. As cyanocobalamine is synthesized by microorganisms, coprophagy may potentially fulfil part of the intake demand in poultry. However, laying hens in cages cannot access this source and thus are entirely dependent on a dietary supply. Vitamin $\mathrm{B}_{12}$ occurs widely in animal tissues and has important physiological functions. Cyanocobalamine interacts with the metabolism of folic acid, participates in the biosynthesis of labile methyl groups and is necessary for the biosynthesis of purine and pyrimidine bases, representing the essential constituents of nucleic acids. Furthermore, it is involved in the biosynthesis of methionine and choline. The most 
obvious signs of deficiency are impaired performance, defective feathering, leg weakness, perosis and gizzard erosion.

Unlike the other B group vitamins, cyanocobalamine can be accumulated in the tissues, mainly in the liver, but also, to a lesser degree, in the kidney, muscles, bone and skin. The capacity of the hen to deposit reserves of vitamin $B_{12}$ is disputed, and there remains an unresolved issue regarding how long body reserves in laying hens may support egg laying until they are depleted. A recent investigation with graded amounts of dietary vitamin $B_{12}(4,8,16 \mathrm{ug} / \mathrm{kg})$, given to breeding hens, showed that egg yolk vitamin $\mathrm{B}_{12}$ concentrations were high at the outset, but decreased markedly within 2 weeks in hens fed the two lowest dietary levels (Squires and Naber, 1992). After 12 weeks on the diets, egg concentrations of vitamin $\mathrm{B}_{12}$ stabilised and were proportional to the amount of vitamin added to the diet. Maximum egg production, egg weight, hen weight and hatchability were obtained when the diet contained $8 \mathrm{ug} / \mathrm{kg}$ of vitamin $\mathrm{B}_{12}$.

\section{NIACIN (NICOTINIC ACID)}

Nicotinic acid is active in the metabolism as nicotinamide and represents an indispensable component of hydrogen-carrying co-enzymes: NAD (nicotinamide adenine dinucleotide) and NADP (nicotinamide adenine dinucleotide phosphate). Nicotinamide participates directly in the transfer of hydrogen, which is of utmost importance in the intermediary metabolism. These biochemical functions are important for normal tissue integrity, particularly for the skin, the gastrointestinal tract and the nervous system. An important part of niacin, present in cereals and their bi-products, is bound and not available for absorption by poultry. The bioavailability of niacin from other feed sources is not clearly documented. Thus, it is obvious, that a dietary supplementation of hens with niacin is necessary. The minimum requirement, indicated by NRC (1994), is $10 \mathrm{mg}$ niacin per $\mathrm{kg}$ feed, based on studies by Ingrose et al. (1965). In a review carried out by Whitehead (2001) the practical level of supplementation for layers was found to be $50 \mathrm{ppm}$ niacin. Based on such information the recommendation for modern laying hens under commercial conditions is considered to be higher.

Jensen et al. (1976) failed to show a significant effect of $44 \mathrm{mg}$ niacin per $\mathrm{kg}$ feed, either alone or in combination with biotin, on egg production, egg weight, feed consumption or body weight changes observed over a 12-week period. In another study with commercial egg-type hens, their response to various levels of niacin supplementation of the diet was investigated (Ouart et al., 1987). Layer performance, feed conversion, nervousness, fertility, and hatchability were observed, but no significant differences were found among the dietary treatments. Leeson et al. (1991) evaluated a dietary niacin supplementation of $22,44,66$ or $132 \mathrm{mg} / \mathrm{kg}$ feed in laying hens through a 364-day trial period. Hens fed 66 or $132 \mathrm{mg} / \mathrm{kg}$ supplemental niacin produced significantly more eggs than birds fed $22 \mathrm{mg} / \mathrm{kg}$. Niacin supplementation was demonstrated to affect shell quality, measured as the degree of shell deformity. A very high dose (up to $1,022 \mathrm{mg} / \mathrm{kg}$ ) showed neither positive nor negative effects on layer performance or health, indicating that niacin is well tolerated, even at supranutritional levels.

\section{PANTOTHENIC ACID}

Pantothenic acid occurs in all animal and plant tissues. Rich sources include yeast, liver, kidney, egg-yolk, cereals and green plants. The absorption of pantothenic acid and its alcohol-derivative in the intestine occurs by passive diffusion. The conversion to coenzyme A (CoA), which represents the conjugated nucleotide form of pantothenic acid, occurs within the tissues. CoA acts as a carrier mechanism for carboxylic acids, which, 
when bound to CoA, become 'active', i.e. have a high potential for transfer to other groups. The most important form is acetyl-CoA, which appears in the citric acid cycle when fat, carbohydrates and certain amino acids are degraded. Acetyl-CoA is also a precursor for the biosynthesis of long-chain fatty acids, phosphatides, cholesterol, steroid hormones and bile acids.

Clinical signs of deficiency include reduced growth, decrease in appetite, poor feed utilization, rough feathering and depigmentation of the feathers. In severe cases, crusts at the corner of the beak as well as exudate on eye-lids can be seen, and fatty degeneration of the liver occurs. Particular to layers, impaired egg production has been reported.

Requirements of this vitamin depend on its interaction with other vitamins such as vitamin $\mathrm{C}$, biotin and vitamin $\mathrm{B}_{12}$, as well as on the fat content of the ration. Low levels of vitamin $B_{12}$ and high levels of fat increase the requirements of pantothenic acid, while the presence of vitamin $\mathrm{C}$ may reduce dietary needs. But overall, insufficient information is available to draw final conclusions on the current pantothenic acid requirement of layers. For an adequate supplementation the genetic improvements of the breeds towards high-yield have to be considered and due to the relationship of pantothenic acid with energy metabolism, must be adjusted to the energy content of the diet. The current recommendation guidelines of the vitamin manufacturers already consider all these factors.

\section{FOLIC ACID (PTEROYLGLUTAMIC ACID)}

Folic acid is present in all green-leaved vegetables, liver, kidney and muscle as well as in milk and cheese. The term 'folates' embraces a group of biologically active compounds which are structurally derived from folic acid. The absorption of folic acid occurs at the jejunum and thereafter it is transported, attached to a protein, to the liver. Limited quantities are present in the liver, and otherwise there is no storage capacity for folates in the body. Enzymatic transformation of folates results into tetrahydrofolic acid (THF), which is an active co-enzyme. THF is involved in various biochemical processes, e.g. methylation reactions and amino acid metabolism, as well as biosynthesis of purines and pyrimidines. The fact that folate activity interacts with many other compounds of the carbon atom metabolism has to be considered for practical recommendations of folic acid fortification in layer diets.

The clinical picture of folic acid deficiency becomes manifest as a result of disturbances of amino acid metabolism and protein synthesis. Rapidly growing tissues, such as epithelia of the gastrointestinal tract or skin and bone marrow, are particularly affected. Retarded growth, diminished appetite, rough plumage and feather depigmentation have also been described. In severe cases cervical paralysis, leg weakness (perosis) and white watery diarrhoea can occur.

When hens were fed a purified folate-deficient diet $(0.07 \mathrm{mg} / \mathrm{kg})$ egg production was reduced (Sherwood et al., 1993). Folates in egg yolk were concentrated approximately 43-fold relative to the blood plasma from which they were derived. Yolk and plasma folate concentrations became saturated with increasing dietary intake. Hens fed a commercial, folate-sufficient diet $(0.72 \mathrm{mg}$ folate $/ \mathrm{kg})$ produced eggs with slightly less than half of the maximal folate content. However, when laying hens were supplemented with $0,2,4,8,16,32,64$ or $128 \mathrm{mg} / \mathrm{kg}$ of crystalline folic acid for 21 days, laying performance was not affected (Hebert et al., 2005). Considering plasma homocysteine concentrations, a strain-specific requirement for folic acid could be deduced as the higher egg mass producing strain benefited from increased folic acid through a reduction in plasma homocysteine concentrations. The main objective of the study above was the enrichment of eggs with folic acid in light of evidence supporting a need for humans to increase their dietary folate intakes. Significant main effects of folate supplementation 
were observed for egg folate content and plasma folate, which was increased. House et al. (2002) reported that, in terms of its nutritional value, one large egg collected from a folic acid-supplemented hen $(4 \mathrm{mg} / \mathrm{kg}$ ) provided approximately $12.5 \%$ of the recommended dietary allowance (RDA) for adult humans (RDA $=400 \mathrm{mg} / \mathrm{day}$ ).

\section{BIOTIN}

Biotin is widely distributed in small concentrations in animal and plant tissues, but is almost entirely unavailable to laying hens from wheat $(0 \%)$ or sorghum $(10-20 \%)$ (Buenrostro and Kratzer, 1984). Biotin is absorbed in the small intestine, transported in the blood stream to the various tissues, but inadequately metabolised. Excess biotin is excreted in both urine and faeces. Biotin represents an important co-enzyme in the intermediary metabolism of carbohydrates, proteins and fats. It is particularly important for carboxylations, since biotin-containing carboxylases take up $\mathrm{CO}_{2}$ and transfer it to a suitable substrate, and a possible effect on purine and pyrimidine synthesis has been put forward. Biotin deficiency results in retarded growth, reduced appetite and poor feed conversion. Rough and brittle feathers, dry skin, dermatitis of foot pads and deformation of the beak can occur. Fatty liver and kidney syndrome (FLKS) as well as perosis develop under biotin insufficiency. In breeder hens, poor hatchability of eggs and malformation of the embryonic skeleton have been observed.

The influence of biotin supplementation on performance of laying hens has been evaluated in two studies. Jensen et al. (1976) provided hens with biotin either alone or in combination with niacin, but could not observe a beneficial effect on egg production, egg weight, feed consumption or body weight over a 12-week period. Likewise, Whitehead (1980) found that biotin supplementation during lay did not have beneficial effects upon egg number, egg size or feed intake/feed conversion efficiency. However, internal egg quality, as reflected by albumen height, was slightly improved by biotin. As to safety, excess feeding up to 25 -times the recommended level had no adverse effect on growth rate, liver weight or liver lipid content of laying hens (Balnave, 1975).

\section{Vitamin C (Ascorbic acid)}

Vitamin $\mathrm{C}$ is widely distributed in high concentrations in plants, particularly in citrus fruits and green vegetables. Birds are capable of synthesising ascorbic acid in their kidneys, but young chicken show insufficient synthesis and, for growing poultry, endogenous production does not meet requirements under intensive husbandry conditions. Ascorbic acid is readily absorbed in the intestine at a high rate (up to $80 \%$ ). Excess vitamin $\mathrm{C}$ or its metabolites are excreted with the urine. Ascorbic acid is concentrated in the adrenal and the pituitary glands, in the brain, the eye lens and in leukocytes. Vitamin $\mathrm{C}$ is a strong antioxidant and is able to quench free radicals and reactive oxygen species. It is essential for the formation of intercellular substances (connective tissue, bones and cartilage) and supports wound healing via its key function, the hydroxylation of proline to hydroxyproline. Furthermore, due to its involvement in corticosteroid synthesis it has an anti-stress activity and it stimulates defensive mechanisms such as phagocytotic activity of leukocytes and formation of antibodies.

Classical vitamin C deficiency does not occur in poultry, but supplemental ascorbic acid was demonstrated to have beneficial effects under stressful conditions. In laying hens kept at high temperatures and in overcrowded conditions, supplemental vitamin $\mathrm{C}$ $(200 \mathrm{ppm})$ reduced mortality, increased slightly shell weight per unit surface area and 
improved Haugh units (Cheng et al., 1990). Vitamins E and C, both potent antioxidants, have been demonstrated to act synergistically in heat-stressed laying hens when monitored as serum levels of tri-iodothyronine (T3) and thyroxine (T4). These parameters were increased by supplementation, however adrenocorticotropic hormone (ACTH) was decreased (Sahin et al., 2002a).

Vitamin $\mathrm{C}$ can exert beneficial effects under low ambient temperature conditions. Sahin et al. (2002b) reported that supplemental vitamin C, either alone or in combination with chromium, significantly increased live weight change, egg production and improved feed efficiency in cold-stressed hens. Egg production and egg weight were also greater in each supplemental group compared with the unsupplemented control group. The benefits of vitamin $\mathrm{C}$ for health of laying hens were also demonstrated in combination with vitamin E (Puthpongsiriporn et al., 2001). Ascorbic acid, supplied as $1,000 \mathrm{ppm} / \mathrm{kg}$ feed during heat stress, generated the highest lymphocyte proliferative responses to concanavalin A and Salmonella typhimurium lipopolysaccharide in comparison to treatments with lower vitamin supplementation. For these reasons, practical recommendations for commercial husbandry conditions should include vitamin C supplementation for laying hens.

\section{Conclusions}

It is now well recognized by the feed industry that the minimum dietary vitamin levels required to prevent clinical deficiencies may not support optimum health, performance and welfare of poultry. The reasons for that are manifold; the productivity of poultry farming has continued to grow through genetic improvement of the breeds and modifications in nutrition, management and husbandry, all of which considerably increase the demand for vitamins. Furthermore, intensive poultry production may generate a certain level of metabolic, social, environmental and disease stresses, causing sub-optimal performance and higher susceptibility to vitamin deficiencies. Contamination of feed with mycotoxins and vitamin antagonists can limit or even block the action of certain vitamins. Any of those factors, ranging from the animal's genetics and health status to management programs and the composition of the diet, can separately or collectively affect the need for each vitamin. As intake and utilisation of vitamins from natural sources is unpredictable due to differing content of vitamins in the feedstuffs and variable vitamin bioavailability, it is safer to cover the entire vitamin requirement of poultry through dietary supplementation.

\section{References}

ABEND, R., JEROCH, H. and HENNIG, A. (1977) The vitamin B6 requirements of the laying hen for reproduction. Archiv für Tierernährung 27: 185-93.

ARIJENIWA, A., IKHIMIOYA, I., BAMIDELE, O.K. and OGUNMODEDE, B.K. (1996) Riboflavin requirement of breeding hens in a humid tropical environment. Journal of Applied Animal Research 10: 163-166.

AWT (Arbeitsgemeinschaft für Wirkstoffe in der Tierernährung) (2002) Vitamins in Animal Nutrition.

BALNAVE, D. (1975) The effects on liver metabolism of administering excesses of biotin to immature pullets and laying hens. British Poultry Science 16: 641-643.

BEYNEN, A.C., SIJTSMA, S.R., KIEPURSKI, A.K., WEST, C.E., BAUMANS, V., VAN HERCK, H., STAFLEU, F.R. AND VAN TINTELEN, G. (1989) Objective clinical examination of poultry as illustrated by the comparison of chickens with different vitamin A status. Laboratory Animals 23: 307-312.

BOLLENGIER-LEE, S., MITCHELL, M.A., UTOMO, D.B., WILLIAMS, P.E. and WHITEHEAD, C.C. (1998) Influence of high dietary vitamin E supplementation on egg production and plasma characteristics in hens subjected to heat stress. British Poultry Science 39: 106-112. 
BOLLENGIER-LEE, S., WILLIAMS, P.E. and WHITEHEAD, C.C. (1999) Optimal dietary concentration of vitamin E for alleviating the effect of heat stress on egg production in laying hens. British Poultry Science 40: $102-107$.

BOURRE, J.M. and GALEA, F. (2006) An important source of omega-3 fatty acids, vitamins D and E, carotenoids, iodine and selenium: a new natural multi-enriched egg. Journal of Nutrition Health \& Aging 10: 371-376.

BUENROSTRO, J.L. and KRATZER, F.H. (1984) Use of plasma and egg yolk biotin of white Leghorn hens to assess biotin availability from feedstuffs. Poultry Science 63: 1563-1570.

CHENG, T.K., COON, C.N. and HAMRE, M.L. (1990) Effect of environmental stress on the ascorbic acid requirement of laying hens. Poultry Science 69: 774-780.

COŞKUn, B., INAL, F., CELIK, I., ERGANIŞ, O., TIFTIK, A.M., KURTOGLU, F., KUYUCUOGLU, Y. and OK, U. (1998) Effects of dietary levels of vitamin A on the egg yield and immune responses of laying hens. Poultry Science 77: 542-546.

DSM (2006) DSM Vitamin supplementation guidelines.

FLEMING, R.H., MCCORMACK, H.A., MCTEIR, L. and WHITEHEAD, C.C. (2003) Effects of dietary particulate limestone, vitamin $\mathrm{K}_{3}$ and fluoride and photostimulation on skeletal morphology and osteoporosis in laying hens. British Poultry Science 44: 683-689.

FLEMING, R.H. (2008) Nutritional factors affecting poultry bone health. Proceedings of the Nutrition Society 67: 177-183.

GALOBART, J., BARROETA, A.C., BAUCELLS, M.D., CORTINAS, L. and GUARDIOLA, F. (2001) Alpha-tocopherol transfer efficiency and lipid oxidation in fresh and spray-dried eggs enriched with omega3polyunsaturated fatty acids. Poultry Science 80: 1496-1505.

GOODSON-WILLIAMS, R., ROLAND SR., D.A. and MCGUIRE, J.A. (1986) Effects of feeding graded levels of vitamin $\mathrm{D}_{3}$ on egg shell pimpling in aged hens. Poultry Science 65: 1556-1560.

GRUNDER, A.A. and TSANG, C.P. (1984) Effects of vitamin $\mathrm{D}_{3}$ deficiency on adenosine triphosphatase activity of jejunums from white Leghorn hens. Poultry Science 63: 1073-1075.

GRUNE, T., KRÄMER, K., HOPPE, P.P. and SIEMS, W. (2001) Enrichment of eggs with n-3 polyunsaturated fatty acids: Effects of vitamin E supplementation. Lipids 36: 833-838.

HEBERT, K., HOUSE, J.D. and GUENTER, W. (2005) Effect of dietary folic acid supplementation on egg folate content and the performance and folate status of two strains of laying hens. Poultry Science 84: 15331538

HOUSE, J.D., BRAUN, K., BALLANCE, D.M., O'CONNOR, C.P. and GUENTER, W. (2002) The enrichment of eggs with folic acid through supplementation of the laying hen diet. Poultry Science $\mathbf{8 1}$ 1332-1337.

INGROSE, R.C., MANOUKAS, A.G. and HINKSON, R. (1965) The niacin requirement of the hen. Poultry Science 44: 1053-1065.

JENSEN, L.S., CHANG, C.H. and MAURICE, D.V. (1976) Effect of biotin and niacin on lipid content of livers in the laying hen. Poultry Science 55: 1771-1773.

JIANG, Y.H., MCGEACHIN, R.B. and BAILEY, C.A. (1994) Alpha-tocopherol, beta-carotene, and retinol enrichment of chicken eggs. Poultry Science 73: 1137-1143.

LAVELLE, P.A., LLOYD, Q.P., GAY, C.V. and LEACH JR., R.M. (1994) Vitamin K deficiency does not functionally impair skeletal metabolism of laying hens and their progeny. Journal of Nutrition 124: 1704.

LEESON, S., CASTON, L.J. and SUMMERS, J.D. (1991) Response of laying hens to supplemental niacin. Poultry Science 70: 1231-1235.

LIN, H., WANG, L.F., SONG, F.L., XIE, Y.M. and YANG, Q.M. (2002) Effect of dietary supplemental levels of vitamin A on the egg production and immune responses of heat-stressed laying hens. Poultry Science 81: 458-465.

NARBAITZ, R., TSANG, C.P., GRUNDER, A.A. and SOARES JR., J.H. (1987) Scanning electron microscopy of thin and soft shells induced by feeding calcium-deficient or vitamin D-deficient diets to laying hens. Poultry Science 66: 341-347.

NRC (1994) Nutrient requirements of poultry.

OLKOWSKI, A.A. and CLASSEN, H.L. (1996) The study of thiamine requirement in broiler chickens. International Journal for Vitamin and Nutrition Research 66: 332-341.

OUART, M.D., HARMS, R.H. and WILSON, H.R. (1987) Effect of graded levels of niacin in corn-soy and wheat-soy diets on laying hens. Poultry Science 66: 467-470.

PUTHPONGSIRIPORN, U., SCHEIDELER, S.E., SELL, J.L. and BECK, M.M. (2001) Effects of vitamin $\mathrm{E}$ and $\mathrm{C}$ supplementation on performance, in vitro lymphocyte proliferation, and antioxidant status of laying hens during heat stress. Poultry Science 80: 1190-1200.

RICHTER, G., MARCKWARDT, E., HENNIG, A. and STEINBACH, G. (1986) Vitamin E requirements of laying hens. Archiv für Tierernährung 36: 1133-1143. 
RICHTER, G., SITTE, E. and PETZOLD, M. (1990) The vitamin A supply of laying hens including during rearing. 2. Effect of varied vitamin A supplementation of mixed feed in rearing on production in the laying period. Archiv für Tierernährung 40: 221-227.

SAHIN, K., SAHIN, N. and YARALIOGLU, S. (2002a) Effects of vitamin C and vitamin E on lipid peroxidation, blood serum metabolites, and mineral concentrations of laying hens reared at high ambient temperature. Biological Trace Element Research 85: 35-45.

SAHIN, K., ONDERCI, M., SAHIN, N. AND AYDIN, S. (2002b) Effects of dietary chromium picolinate and ascorbic acid supplementation on egg production, egg quality and some serum metabolites of laying hens reared under a low ambient temperature (6 degrees C). Archiv für Tierernährung 56:41-49.

SCHEIDELER, S.E. and FRONING, G.W. (1996) The combined influence of dietary flaxseed variety, level, form, and storage conditions on egg production and composition among vitamin E-supplemented hens. Poultry Science 75: 1221-1226.

SHERWOOD, T.A., ALPHIN, R.L., SAYLOR, W.W. and WHITE $3^{\text {RD }}$, H.B. (1993) Folate metabolism and deposition in eggs by laying hens. Archives of Biochemistry and Biophysics 307: 66-72.

SOARES, J.H., KERR, J.M. and GRAY, R.W. (1995) 25-hydroxycholecalciferol in poultry nutrition. Poultry Science 74: 1919-1934.

SOTO-SOLANOVA, M.F. and HERNANDEZ, J.M. (2004) Practical study on the effect of feeding an optimum vitamin nutrition and 25-hydroxycholecalciferol on production and egg quality of layers. Proceedings XXII World's Poultry Congress, p 371.

SOTO-SOLANOVA, M. and SCHLIFFKA, W. (2007) Effect of Rovimix Hy•D in laying hen production. Proceedings 16th European Symposium on Poultry Nutrition, p. 360.

SQUIRES, M.W. and NABER, E.C. (1992) Vitamin profiles of eggs as indicators of nutritional status in the laying hen: Vitamin $\mathrm{B}_{12}$ study. Poultry Science 71: 2075-2082.

SQUIRES, M.W. and NABER, E.C. (1993a) Vitamin profiles of eggs as indicators of nutritional status in the laying hen: Vitamin A study. Poultry Science 72: 154-164.

SQUIRES, M.W. and NABER, E.C. (1993b) Vitamin profiles of eggs as indicators of nutritional status in the laying hen: Riboflavin study. Poultry Science 72: 483-494.

SÜNDER, A., HALLE, I. and FLACHOWSKY, G. (1999) Vitamin E hypervitaminosis in laying hens. Archiv für Tierernährung 52: 185-194.

SÜNDER, A. and FLACHOWSKY, G. (2001) Influence of high vitamin E dosages on retinol and carotinoid concentration in body tissues and eggs of laying hens. Archiv für Tierernährung 55: 43-52.

TAKAHASHI, N., SHINKI, T., ABE, E., HORIUCHI, N., YAMAGUCHI, A., YOSHIKI, S. and SUDA, T. (1983) The role of vitamin D in the medullary bone formation in egg-laying Japanese quail and in immature male chicks treated with sex hormones. Calcified Tissue International 35: 465-471.

TSANG, C.P. and GRUNDER, A.A. (1993) Effect of dietary contents of cholecalciferol, 1 alpha,25dihydroxycholecalciferol and 24,25-dihydroxycholecalciferol on blood concentrations of 25hydroxycholecalciferol, 1 alpha,25-dihydroxycholecalciferol, total calcium and eggshell quality. British Poultry Science 34: 1021-1027.

WHITEHEAD, C.C. (1980) Performance of laying hens fed on practical diets containing different levels of supplemental biotin during the rearing and laying stages. British Journal of Nutrition 44: 151-159.

WHITEHEAD, C.C. (2001) Nicotinic acid in poultry nutrition. Feed Mix 9: 32-34. 
458 World's Poultry Science Journal, Vol. 65, September 2009

Downloaded from https:/www.cambridge.org/core. University of Basel Library, on 11 Jul 2017 at 10:30:15, subject to the Cambridge Core terms of use, available at https:/www.cambridge.org/core/terms. https://doi.org/10.1017/S0043933909000312 